\title{
Study of fuel octane sensitivity effects on gasoline partially premixed combustion using optical diagnostics
}

\author{
Author, co-author (Do NOT enter this information. It will be pulled from participant tab in \\ MyTechZone) \\ Affiliation (Do NOT enter this information. It will be pulled from participant tab in MyTechZone)
}

\begin{abstract}
Partially premixed combustion (PPC) is a low-temperature combustion concept that could deliver higher engine efficiency, as well as lower emissions. Gasoline-like fuel compression ignition (GCI) is beneficial for air/fuel mixing process under PPC mode because of the superior auto-ignition resistance to prolong ignition delay time. In current experiments, three surrogate fuels with same research octane number (RON77) but different octane sensitivities (OS), PRF77 ( $\mathrm{S}=0)$, TPRF77-a $(\mathrm{S}=3$ ) and TPRF77-b $(\mathrm{S}=5)$, are tested in a full-transparent single cylinder AVL optical compression ignition (CI) engine at low load conditions.
\end{abstract}

Aiming at investigating the fuel octane sensitivity effect on engine combustion behavior as well as emissions under GCI-PPC mode, engine parameters, and emission data during combustion are compared for the test fuels with a change of injection timing. In addition, in order to get a deeper insight into fuel OS effect on GCIPPC mode, high-speed natural flame luminosity (NFL) imaging techniques are used for visualizing in-cylinder combustion processes. The results show that higher octane sensitivity generally lead to delayed start of combustion, prolonged ignition delay time, retarded combustion phasing of CA50 as well as extended combustion duration. At late injection timing of -15 CAD aTDC, higher IMEP is achieved with higher OS fuel along with lower maximum in-cylinder pressure. A 4\% increase of IMEP is achieved by the test fuel with highest OS (TPRF77-b) as compared with zero sensitivity fuel (PRF77). Moreover, the fuel spray vaporization process is affected by fuel octane sensitivity, which introduces some bright tiny spots during the combustion process as well as higher UHC and CO emissions, especially for early injection timing.

\section{Introduction}

Nowadays, with the massive application of internal combustion engine (ICE) and increasing demand for energy provided by fossil fuel, the exhausted pollutants are becoming a major concern to the human health and environment. Thus, advanced low-temperature combustion (LTC) concepts, such as homogeneous charge compression ignition (HCCI) and partially premixed combustion (PPC) technologies, have been researched to achieve higher engine efficiency, lower fuel consumption, as well as lower emissions [1].

Page 1 of 12
For HCCI, fuel is injected very early to obtain fully premixed air/fuel mixture, thus engines can deliver high efficiency and low NOx emissions. However, the intense heat release rate and pressure rise rate of HCCI are dominated by fuel chemical kinetics, put a constraint on the power output $[2,3]$. Instead of HCCI, PPC technology has been researched for practical applications as it could apply flexible fuel injection strategy to achieve favorable control over mixture stratification level, combustion phasing and pressure rise rate $[4,5]$.

In terms of real applications, quite much exhaust gas recirculation (EGR) needs to be introduced when PPC mode was firstly applied in commercial heavy-duty (HD) [6, 7] and light-duty (LD) [8-10] diesel engine to control in-cylinder auto-ignition, especially at high load conditions. However, Shen et al [11] reported that too much EGR led to lower combustion efficiency and higher hydrocarbon (UHC) and $\mathrm{CO}$ emissions. Therefore, gasoline PPC was applied to increase the auto-ignition resistance, so as to achieve longer ignition delay and better fuel stratification. Manente et al [12-14] reported that the engine gross indicated mean effective pressure (IMEP) range could be extended to up to 25 bar when using gasoline PPC technology, while the NOx and particulates emissions could be kept at low level. Kalghatgi et al. [15, 16] also reported that gasoline-fueled PPC could achieve lower NOx and PM emissions compared with diesel fuel. However, in order to improve the combustion stability of gasoline PPC at low load, high-reactivity (low-octane) gasoline-like fuel are proposed to promote in-cylinder auto-ignition and combustion stability. Leermarkers et al. [17] investigated the property effect of fuel with the same RON (research octane number) of 70 on engine performance and reported that high-reactivity gasoline PPC had good potential for engine efficiency both at mid and high loads for all tested fuels. Besides, the previous studies in authors' group applied high-reactivity (RON from 50 to 77) gasoline-like fuel to achieve stable gasoline PPC with low intake temperature, and multipleinjection strategy can further improve combustion stability with lower intake temperature [10].

The above studies have verified the feasibility of applying high reactivity gasoline-like fuel to achieve efficient combustion with suitable phasing control, and surrogate fuel have been widely used to mimic the real fuel behavior under various operation conditions of future IC engines. Among them, the primary reference fuel (PRF) and toluene primary reference fuel (TPRF) are frequently used because 
they are flexible to match the RON and MON (motor octane number) of various of base fuel. For example, Chang J et al. [18] and Shankar et al. [19] had used PRF to study the start of the high-temperature reaction (HTR) of gasoline and combustion phasing in SI engine. However, PRF shows obvious negative temperature coefficient (NTC) behavior as it is only composed of paraffinic components (i.e., n-heptane and iso-octane), the enhanced motor octane qualities lead to zero octane sensitivity (OS) [25], which is defined as the difference between RON and MON (Eq. 1), and this could be calibrated in CFR engine under standard conditions [20] and associated testing protocols [21]. Consequently, more complex surrogate with three or more components (e.g., TPRF) is needed to represent the reactivity of gasoline and naphtha-type fuel. Sarathy et al. [22] applied surrogates to study the octane sensitivity of FACE gasoline and showed that toluene could be used to imitate much of the aromatics in gasoline.

$$
S=R O N-M O N
$$

As gasoline fuel generally have high aromatic (20-30\%) and nonparaffinic (5-10\%) contents, they exhibit a series of fuel sensitivities, which influence the ignition and combustion behavior of fuel [23, 24]. Leppard [25] studied the chemical origin of OS and showed that low sensitivity fuel exhibited distinguished two-stage ignition behavior while the high sensitivity fuel not. These effects were explained by Westbrook et al. [26] through local electron delocalization, they also studied the molecular structure effects on OS in SI engines by using chemical kinetic modeling approach. Siddharth et al. [27] examined the OS effects on high reactivity gasoline-like surrogates in homogeneous mixtures and diesel sprays and showed that OS had strong influences on ignition delay curve at low and intermediate temperatures, but relatively small influence at high temperatures. Javed et al. [28, 29] illustrated that high sensitivity fuel reacted slowly at low temperatures while gaining high reactivity at high temperatures, and displayed temperature-dependent NTC behavior. In addition, Singh et al. [30] and Szybist et al. [31] denoted that the fuel in SI engine obtained higher latent heat of vaporization and reduced pre-spark heat release when increasing the fuel sensitivity.

In overall, most of the researches above were mainly focused on the fuel in SI engine, while seldom studies had been carried out on OS influences on GCI engine. Thereby, this paper is aimed to investigate the OS effect of fuel on combustion behavior, such as combustion phasing, heat release rate and emission characteristics. The experiments are implemented in an AVL fully-transparent single cylinder diesel engine, which works at load conditions and the work output is evaluated based on indicated mean effective pressure (IMEP). One binary blend (PRF77) and two ternary blends (TPRF77a, TPRF77-b), with varying fuel sensitivity are considered while keeping the same octane number $(\mathrm{RON}=77)$. The composition ratios for different components (toluene, iso-octane and n-heptane) in these surrogate fuel, are calculated based on the linear-by-volume (LbV) model illustrated by Morgan et al. [32], and the test fuel properties are listed in Table 1. In addition, a sweep of injection timing is applied in the experiment to study on the OS effects on engine behavior at different zones under PPC mode. Moreover, the natural flame luminosity (NFL) imaging technology is applied to get a deeper insight into OS effects on combustion processes as well.
Table 1. Test fuel properties [32]

\begin{tabular}{|l|l|l|l|}
\hline Fuel & PRF77 & TPRF77-a & TPRF77-b \\
\hline RON & 77 & 77 & 77 \\
\hline MON & 77 & 74 & 72 \\
\hline Sensitivity & 0 & 3 & 5 \\
\hline Toluene (\% volume) & 0 & 25 & 45 \\
\hline $\begin{array}{l}\text { N-heptane (\% } \\
\text { volume) }\end{array}$ & 23 & 47 & 23 \\
\hline $\begin{array}{l}\text { Iso-octane (\% } \\
\text { volume) }\end{array}$ & 77 & 28 & 32 \\
\hline Density (kg/m3) & 688.6 & 731.4 & 768.3 \\
\hline Heat value (MJ/kg) & 35.5 & 40.2 & 39 \\
\hline
\end{tabular}

\section{Experimental setup and methodology}

\subsection{Optical setup and test fuel}

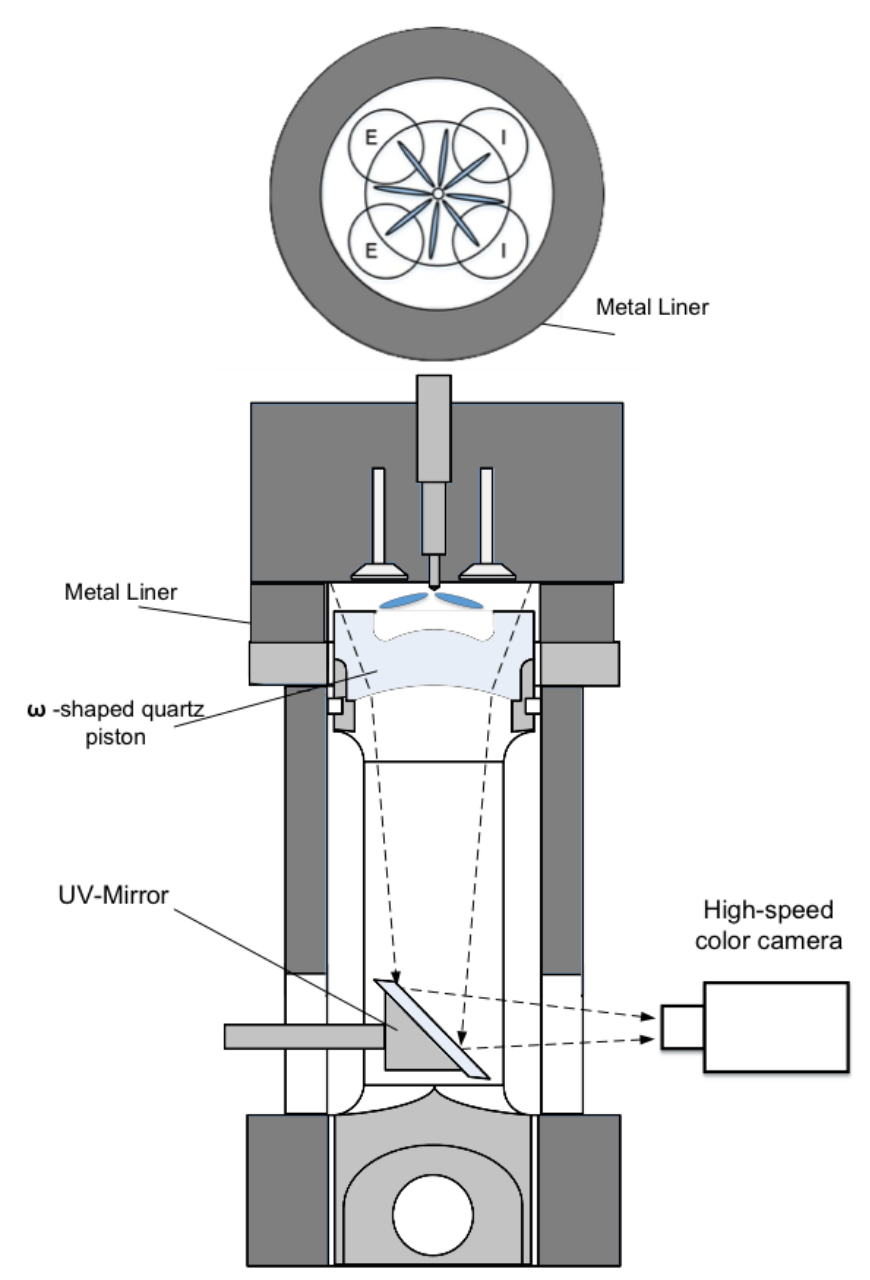

Figure 1. The optical diagnostic schematic

The engine specifications and operating parameters are listed in Table 2 and the setup diagram is shown in Figure 1. The outer diameter and height of liner are $135 \mathrm{~mm}$ and $29 \mathrm{~mm}$ respectively, and the piston bowl diameter is $50.8 \mathrm{~mm}$. The full-transparent optical piston is composed of a $\omega$-shape piston crown and metal piston body, which is installed into the AVL optical engine together with the metal liner. The view through the Bowditch piston into the bowl is 
sufficient for the current investigation. In addition, a vacuum pump is fitted to the engine to prevent oil splash from the crankcase to optical components. During operation, the intake pressure and temperature are controlled by a pressure regulator and a PID controlled heater respectively. In order to keep the peak in-cylinder pressure at 35 bar during motoring cycle, the intake air pressure is boosted to $1.5 \mathrm{bar}$. The intake temperature is set at $140^{\circ} \mathrm{C}$ to trace the combustion development with all injection timings. The coolant pressure and temperature are regulated by an AVL PUMA system. In addition, the IAV FI2RE commander software is communicating with the electronic control unit (ECU) to govern the injection timing and injection pulse width. The injection mass is set at $10 \mathrm{mg}$, and the injection duration is kept at $8 \mathrm{CAD}$. Moreover, the fuel is injected by a wide spray injector with umbrella angle $162^{\circ}$ in this study.

The in-cylinder combustion processes were recorded by a high-speed color camera (FASTCAM SA4, Photron) with a $50 \mathrm{~mm}, \mathrm{f} / 1.4 \mathrm{BK} 7-$ glass lens, via a UV-mirror from the bottom of quartz piston. Besides, the camera frame rate was set at 10000 frames per second with the resolution of $512 \times 512$, while the exposure time was set $100 \mu \mathrm{s}$. The emission measurements were implemented with AVL AMA i60 exhaust measurement system, such as $\mathrm{CO}$ and UHC, which were based on the non-dispersive infrared detector (NDIR) principle and flame ionization detector respectively. Afterward, 150 consecutive firing cycles were recorded.

Table 2. The engine specifications and operating conditions

\begin{tabular}{|c|c|c|c|}
\hline Engine speed & $\begin{array}{c}1200 \\
\text { rpm }\end{array}$ & Injection pressure & 600 bar \\
\hline Bore & $85 \mathrm{~mm}$ & Injection timing & $\begin{array}{l}-80 \text { to }-15 \\
\text { CAD aTDC }\end{array}$ \\
\hline $\begin{array}{l}\text { Compression } \\
\text { ratio }\end{array}$ & 9.5 & Injection duration & $\sim 8 \mathrm{CAD}$ \\
\hline Swept volume & $511 \mathrm{cc}$ & \multirow{2}{*}{$\begin{array}{l}\text { Motoring in-cylinder } \\
\text { pressure at TDC }\end{array}$} & \multirow[b]{2}{*}{35 bar } \\
\hline $\begin{array}{l}\text { Nozzle hole } \\
\text { diameter }\end{array}$ & $0.18 \mathrm{~mm}$ & & \\
\hline Injector holes & 8 & Coolant temperature & $80^{\circ} \mathrm{C}$ \\
\hline $\begin{array}{l}\text { Injection } \\
\text { umbrella angle }\end{array}$ & $162^{\circ}$ & Lubricant temperature & $80{ }^{\circ} \mathrm{C}$ \\
\hline Injection mass & $10 \mathrm{mg}$ & Intake air temperature & $140^{\circ} \mathrm{C}$ \\
\hline
\end{tabular}

\section{Result and discussion}

\subsection{Combustion characteristics}

During the combustion process, the combustion phasing is correlated with engine efficiency and power output, which can be characterized by CA10 and CA50, and they represent the crank angle degree (CAD) at which $10 \%$ and $50 \%$ of the total heat are released respectively. In addition, the start of combustion (SOC) phasing is generally represented by CA10, and the interval between the start of injection (SOI) and SOC is considered as the ignition delay time (IDT), which is an important indicator for in-cylinder lowtemperature reaction process. The pressure and heat release results with regards to different injection timing can be seen in the appendix.

Figure 2 shows the IDT for different OS fuels with regards to different SOIs for three different OS fuels. Besides, as the aromatic component of toluene has a higher anti-ignition capability [25], thus a Page 3 of 12 slightly increased IDT is noted for higher OS fuel. This result is consistent with the previous research of Westbrook et al. [26].

Moreover, in order to quantify the fuel sensitivity effects, the relative deviations (RD) of some parameters of fuel with higher OS $(S=3,5)$ compared with those of PRF77 $(\mathrm{S}=0)$, are calculated at three different SOIs: $-60,-35$ and -15 CAD aTDC, shown in Eq. 2.

$$
R D_{X}=\frac{\Delta X}{X_{1}}=\frac{X_{2}-X_{1}}{X_{1}}
$$

Where $X_{1}, X_{2}$ denote the parameters of PRF77 ( $\left.\mathrm{S}=0\right)$ and higher OS fuel repectively.

As are shown in Fig. 3, these three SOIs are related with the transition zone between HCCI and PPC, typical PPC, and transitional zone between PPC and CI respectively, and the combustion characteristics in these zones present different features [33].

As can be seen in Fig.2, the relative deviations of IDT are kept under $15 \%$ with regards to different SOIs, however, the fuel OS effect on the IDT become much weaker when advancing the injection timing, because the IDTs for three test fuels are prolonged when advancing injection timing, thus the relative deviation brought by fuel OS is reduced. Furthermore, Although these three test fuels have the same RON of 77, the higher OS fuel ( $S=5$ ) has the longest IDT because the highest percentage of toluene suppress the low-temperature reaction process and extend the IDT.

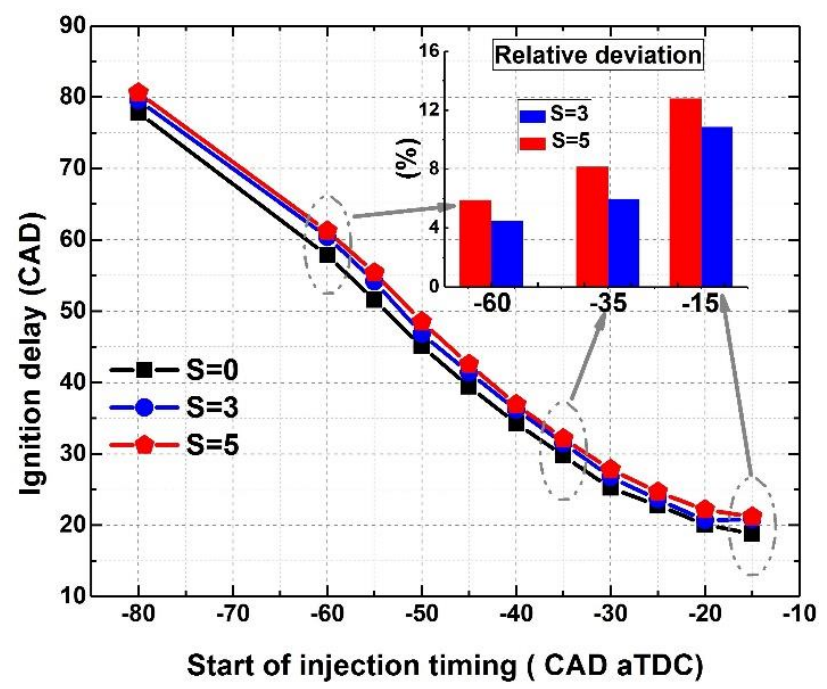

Fig. 2. The ignition delay and relative deviation for three test fuels at various injection timing 


\section{SOI}

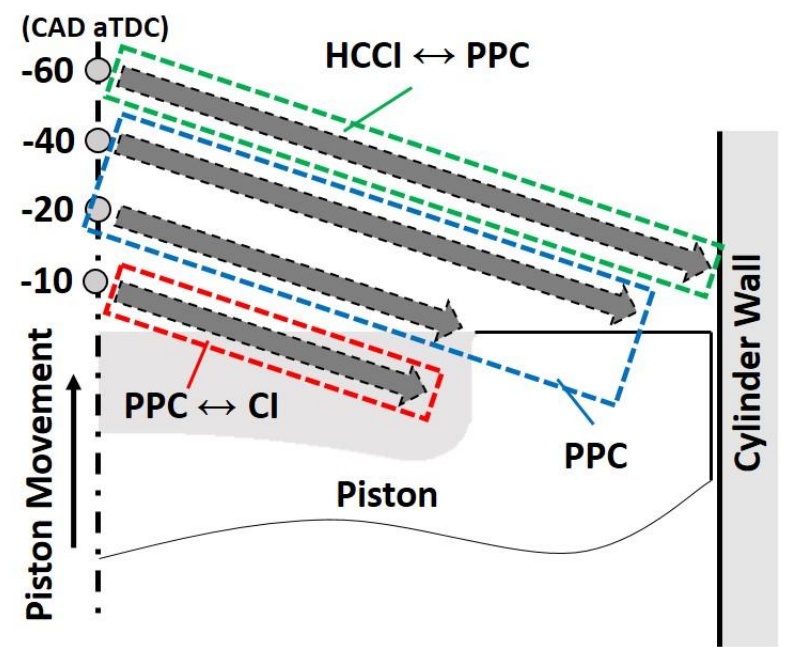

Fig. 3. Different fuel spray/wall interaction zones

As is shown in Fig. 4, the SOC of all three test fuels follow the similar trends along with different SOIs, these trends are consistent with the previous result of Ref. [34]. However, some differences could be found here, the higher sensitivity fuel generally suppresses the in-cylinder auto-ignition and leads to retarded SOC. In the late PPC mode with SOI varying from -20 to -10 CAD aTDC, the higher sensitivity fuel has more retarded CA50 after TDC, which is beneficial for the engine efficiency and power output, since more heat and power are generated during the expansion stroke. In addition, the fuel OS shows the obvious effect on SOC after quantitatively analyzing the relative deviations of SOC for higher OS test fuels $(S=3,5)$. Especially, the stronger effect of fuel OS on SOC is noted in the transitional zone between HCCI and PPC (over 100\%), which denotes that toluene is able to suppress the LTR process of fuel.

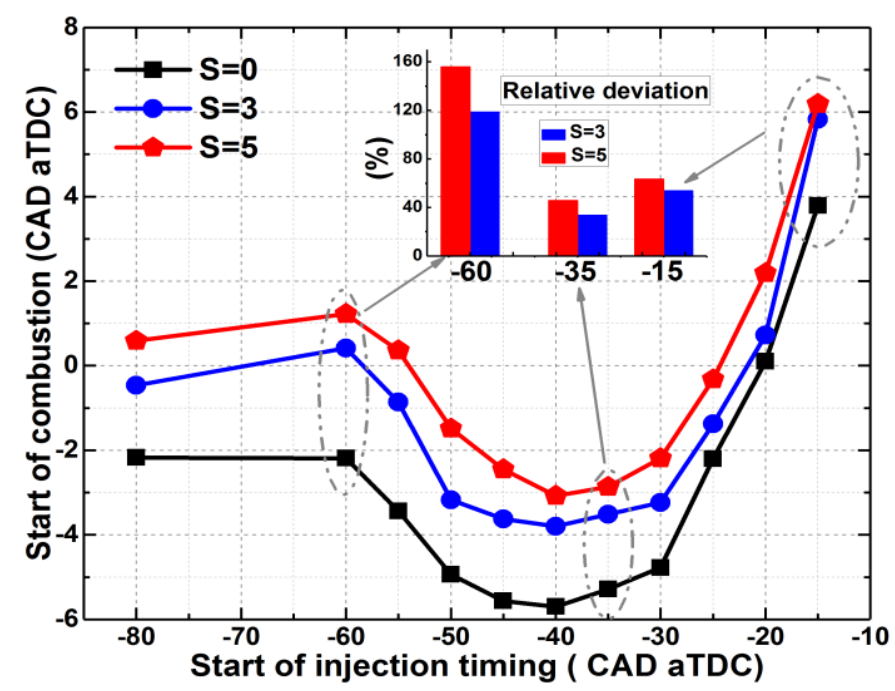

Fig. 4. The SOC phasing and relative deviation for three test fuels at various injection timing

Page 4 of 12

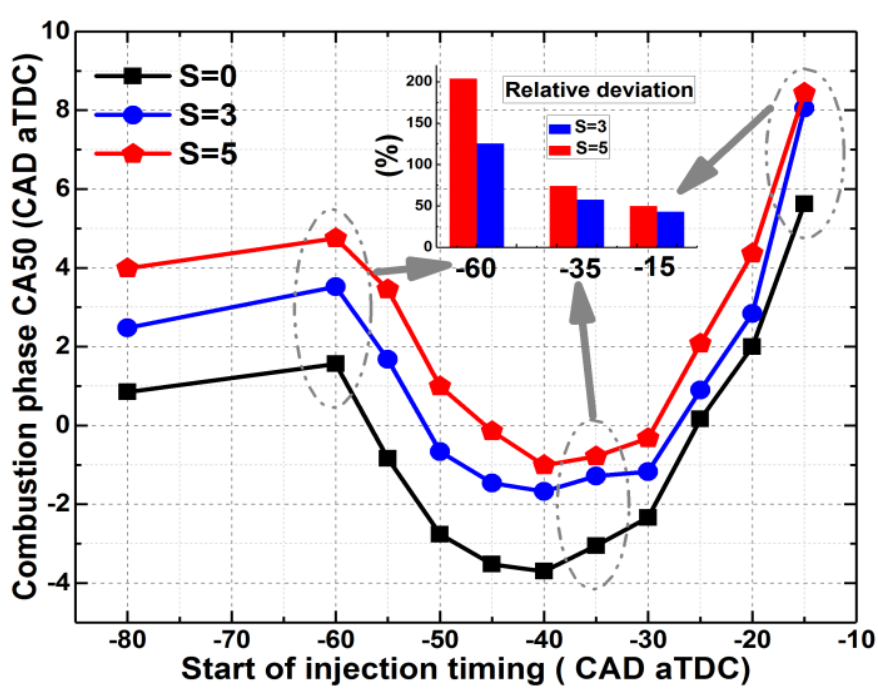

Fig. 5. The CA50 and relative deviation for three test fuels at various injection timing

Fig. 5 plots CA50 variations for three test fuels along with different SOIs, and the trend is consistent with the previous result of Ref. [34]. Notably, fuel OS also has an important effect on CA50. For example, in the intermediate PPC mode with SOI varying from -50 to -30 CAD aTDC, the higher sensitivity fuel has more retarded CA50 after TDC, which is beneficial for the engine efficiency and power output, since more heat and power are generated during the expansion stroke. Moreover, the relative deviations of higher OS test fuel denote that the OS gives significant impacts on CA50 especially in the transitional zone between HCCI and PPC (over 100\%) because the in-cylinder combustion process is mainly dominated by fuel chemistry kinetics reaction with more homogeneous air/fuel mixture is formed in this zone. In comparison, the influences of fuel OS on SOC and CA50 become weaker in the typical PPC zone and the transitional zone between PPC and CI, because more air/fuel mixture stratification is formed, and the combustion behavior is more affected by fuel injection timing rather than the fuel chemistry.

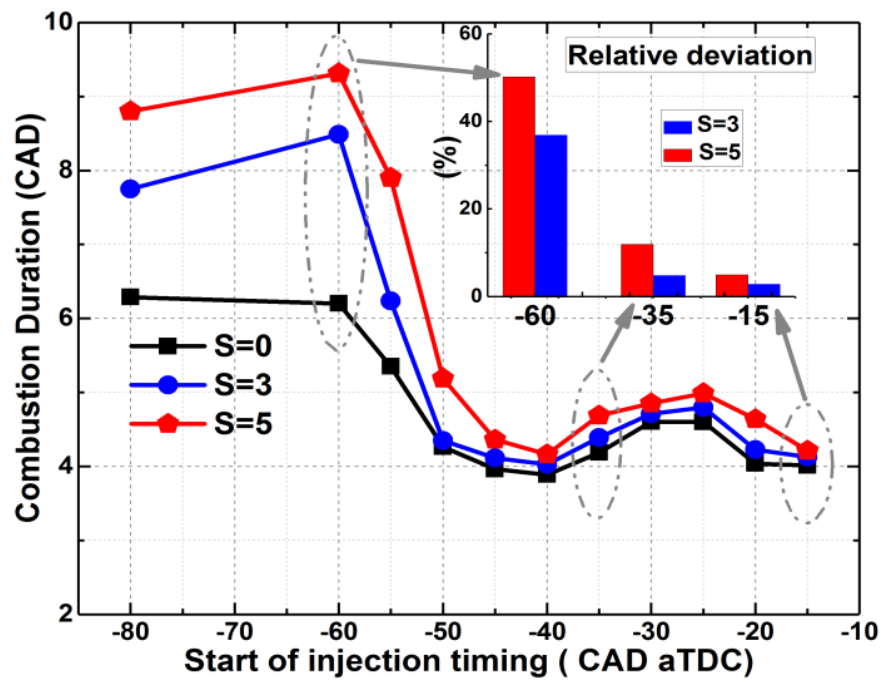

Fig. 6. The combustion duration and relative deviation for three test fuels at various injection timing 


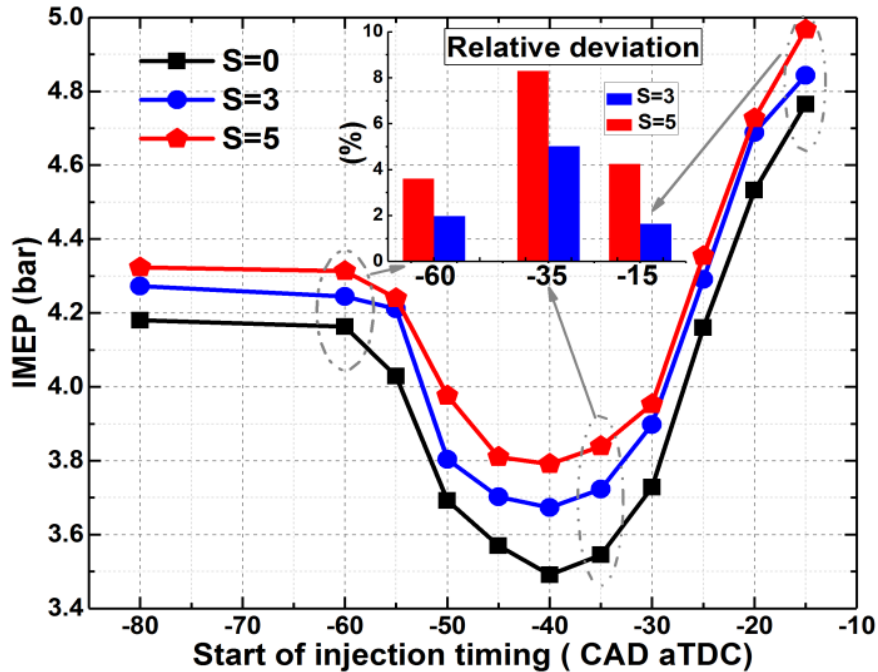

Fig. 7. The CA50 and relative deviation for three test fuels at various injection timing

Fig. 6 plots the variations of combustion duration for three test fuels, which is defined as the interval between CA10 and CA90 (the crank angle at which $90 \%$ of the total heat released). In comparison of these three curves, the test fuel with higher OS has longer combustion duration. Moreover, the stronger effect of fuel OS on combustion duration deviations was observed in the transition zone between HCCI and PPC. For example, the combustion duration was prolonged by $37 \%$ and $50 \%$ respectively when compared with the zero OS of pure PRF fuel. This arises from the fact that the production of reactive radicals from paraffin ( $n$-heptane and iso-octane) becomes slowly at low temperature, meanwhile a large number of radicals (e.g. $\mathrm{OH}$ ) are consumed by toluene during the initial oxidization reactions [34]. Consequently, the high fuel OS not only be capable to extend the ignition delay, but also to expand the combustion duration, thus the test fuel with higher OS leads to prolonged combustion duration.

Fig. 7 reveals the variations of IMEP for three test fuels $(S=0,3,5)$ with regards to different SOIs under PPC mode. In comparison, the fuel with high sensitivity is beneficial for improving engine performance with higher IMEP. Referring to the IMEP of PRF77 $(\mathrm{S}=0)$, the maximum relative deviation brought by TPRF77-a $(\mathrm{S}=3)$ is near $5 \%$, while it is higher than $8 \%$ for TPRF77-b $(S=5)$. Since the heat value of TPRF77-a is the highest among three test fuels, it should be fuel sensitivity rather than heat value contribute more to improving the IMEP. Consequently, the engine fuel with high sensitivity is able to improve the IMEP, because the delayed combustion phasing and extended combustion duration lead to lager proportion of heat released during the engine expansion stroke. Furthermore, the influence from fuel sensitivity becomes more obvious at the SOI of -35 CAD compared with other SOIs, this implies that the fuel sensitivity has a greater impact on the IMEP in the typical PPC zone.

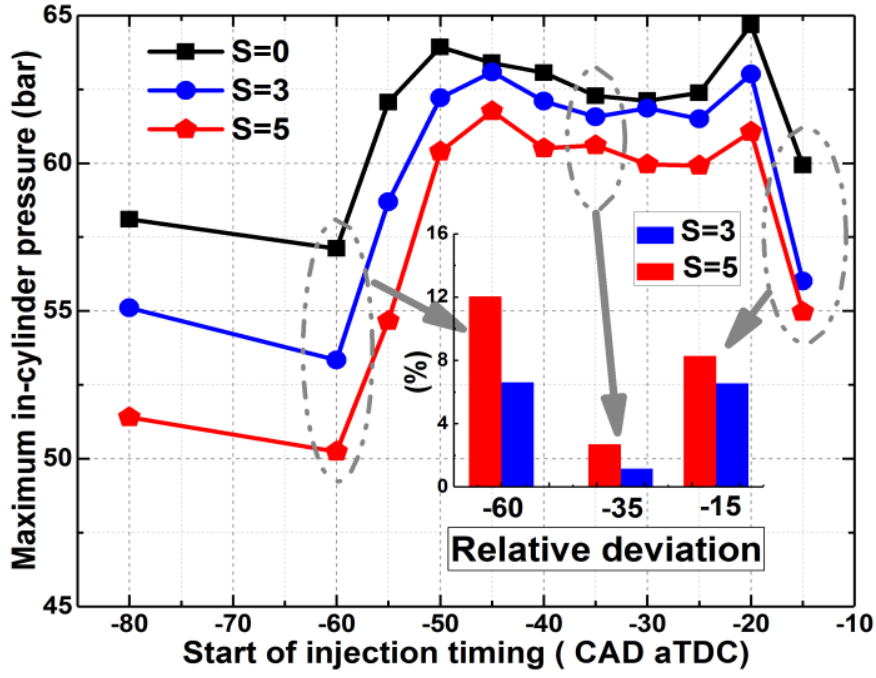

Fig. 8. The Pmax and relative deviation for three test fuels at various injection timing

Fig. 8 demonstrates the maximum in-cylinder pressure (Pmax) changes of three test fuels with different OS, and they follow the same trends along with variations of SOIs. After comparing three curves for three test fuels, the one with higher OS is more likely has lower maximum in-cylinder pressure while higher relative deviation at different SOIs, this is resulted from the fact that retarded CA50 with higher OS leads to lower burning velocity and slower heat release, hence brings more gentle in-cylinder pressure. Furthermore, the OS influence is obviously degraded in typical PPC zone, this is because the peak pressure is much higher in this zone, which contributes to relative low deviation of Pmax.

\subsection{Emissions}

Fig. 9 plots the UHC emission of three test fuels along with different SOIs, and the same UHC emissions trends were noted along with SOI variations. Firstly, the UHC emission is kept stable at a high level when delaying the SOI from -80 to $-60 \mathrm{CAD}$ aTDC, which is due to incomplete combustion resulted from low in-cylinder temperature. In addition, compared with zero OS fuel of PRF77, the two ternary blending fuels with the higher OS $(S=3,5)$ tend to produce higher UHC emission, which implies that the high OS fuel is less prone to combustion, especially at low temperature. Afterwards, with further retarding the SOI from $-60 \mathrm{CAD}$ aTDC, the UHC emissions of the three test fuels, as well as the relative deviations, decrease significantly to relatively low level, this is attributed to more complete combustion led by higher in-cylinder temperature, and it also denotes that the effect of fuel OS on UHC emission is less efficient at high temperature. 


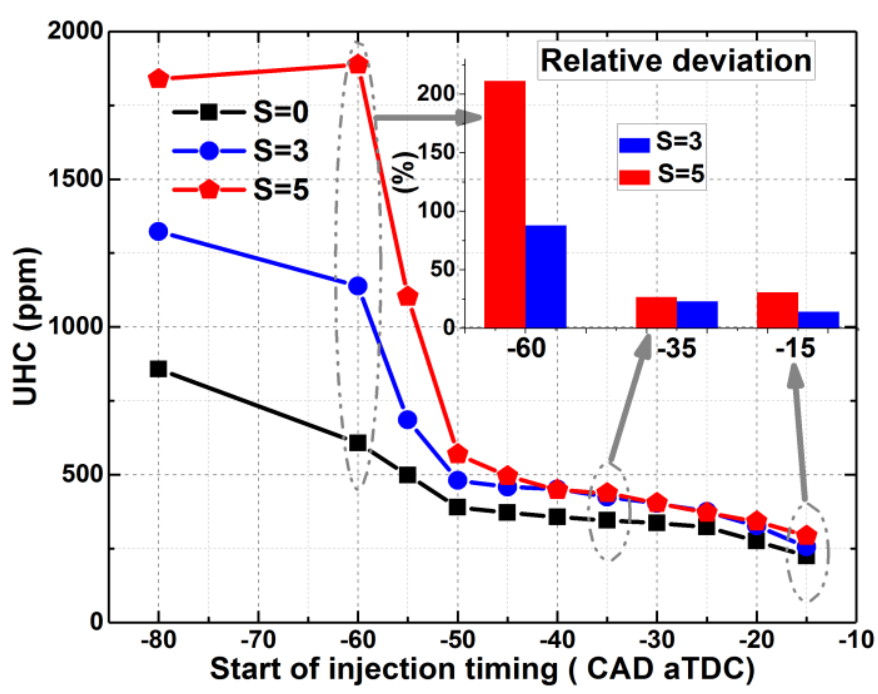

Fig. 9. The UHC emission and relative deviation for three test fuels at various injection timing

As can be seen in Fig. 10, the CO emissions for test fuels with different OS vary similarly at different SOIs. In the transition zone between HCCI and PPC modes, the higher level of CO emission was observed due to the incomplete combustion formed by low incylinder temperature, especially for higher OS test fuel. With retarding of the SOI from $-60 \mathrm{CAD}$ aTDC, the $\mathrm{CO}$ emissions of the three test fuels decline significantly and reach to the lower values when the injection timing locates at -45 CAD aTDC, since the incylinder temperature becomes higher in this engine condition. Nonetheless, the $\mathrm{CO}$ emissions rise obviously when the injection timing varies from -45 to $-30 \mathrm{CAD}$ aTDC, this phenomenon is called "CO jump" and which is caused by the fact that more fuel was trapped in the crevice zone between piston and cylinder wall during this injection timing variation, as shown in Fig. 3. After that, the $\mathrm{CO}$ emissions decrease very fast when the injection timing is further retarded from -30 CAD aTDC, and this is attributed to the strong CO oxidation with higher in-cylinder temperature.

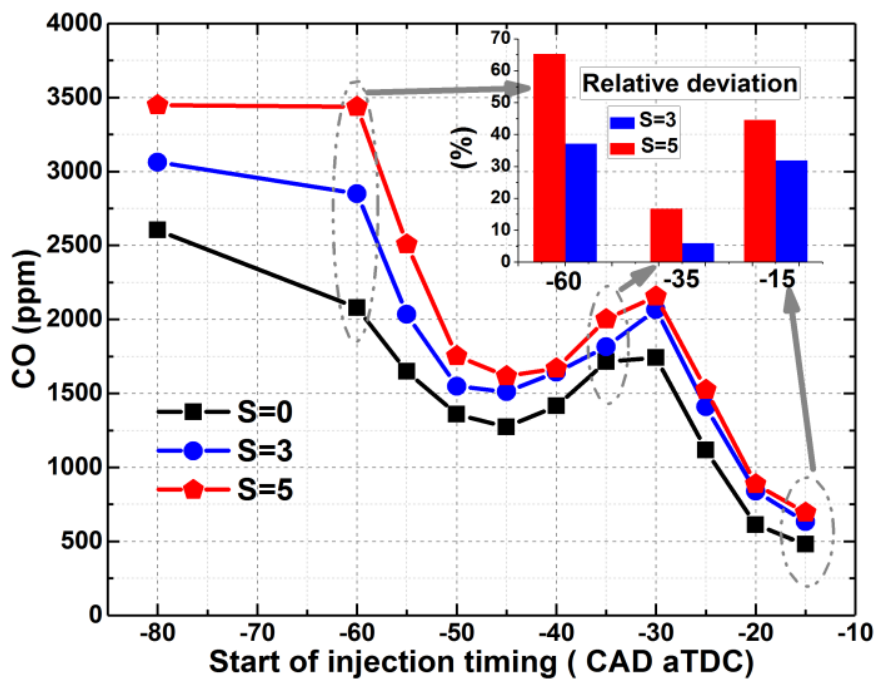

Fig. 10. The CO emission and relative deviation for three test fuels at various injection timing

Page 6 of 12

\subsection{High-speed natural flame luminosity imaging}

Fig. 11 presents the in-cylinder combustion NFL images for test fuels with different sensitivities $(S=0,3,5)$ at fuel injection timing of -60 $\mathrm{CAD}$ aTDC. In order to trace the whole combustion process, the incylinder NFL images are recorded every 5 CAD from TDC.

Moreover, this interval is reduced during the early high-temperature combustion period to capture flame kernel development process. The luminous intensities of these images have been amplified by certain factors, in order to clearly visualize and compare the in-cylinder combustion development processes. Fig. 12 shows the average pixel intensity variations along with the crank angle changes. Moreover, in these NFL images, the chemiluminescence of blue channel comes from decomposition of fuel molecules, which represents for the early period of high-temperature reaction. The color camera relative spectral response is shown in the Fig. 8 of the appendix. Besides, the bright and dark yellow zones indicate the soot radiation during the high-temperature combustion process [33].

According to Fig. 11, the combustion radiation from the test fuels is not intense, since the in-cylinder temperature is very low with early injection timing. Notably, there is some blue flame appears in the combustion images after TDC for test fuels with OS of 3 and 5, and several tiny bright spots emerge in the images for test fuel with highest sensitivity $S=5$. These phenomena are due to the fact that the heat capacity of higher OS test fuel is increased with adding toluene inside, thus it needs to absorb more heat for vaporization, which results to slowly fuel decomposition as well as delayed phasing for blue channel chemiluminescence. Similarly, as the highest OS test fuel with $\mathrm{S}=5$ is not completely burnt in this process, then some rich mixture zone leads to the formation of tiny bright spots.

As can be seen in Fig. 12, the average pixel intensity becomes higher after TDC for higher OS test fuels ( $\mathrm{S}=3$ and 5), especially for the fuel with the highest OS of 5. As is illustrated before, the fuel sensitivity is able to extend ignition delay and retard combustion phasing at low temperature, which results in delayed heat release during combustion as well as an intensity change. 
SOI: -60 CAD aTDC (x10)

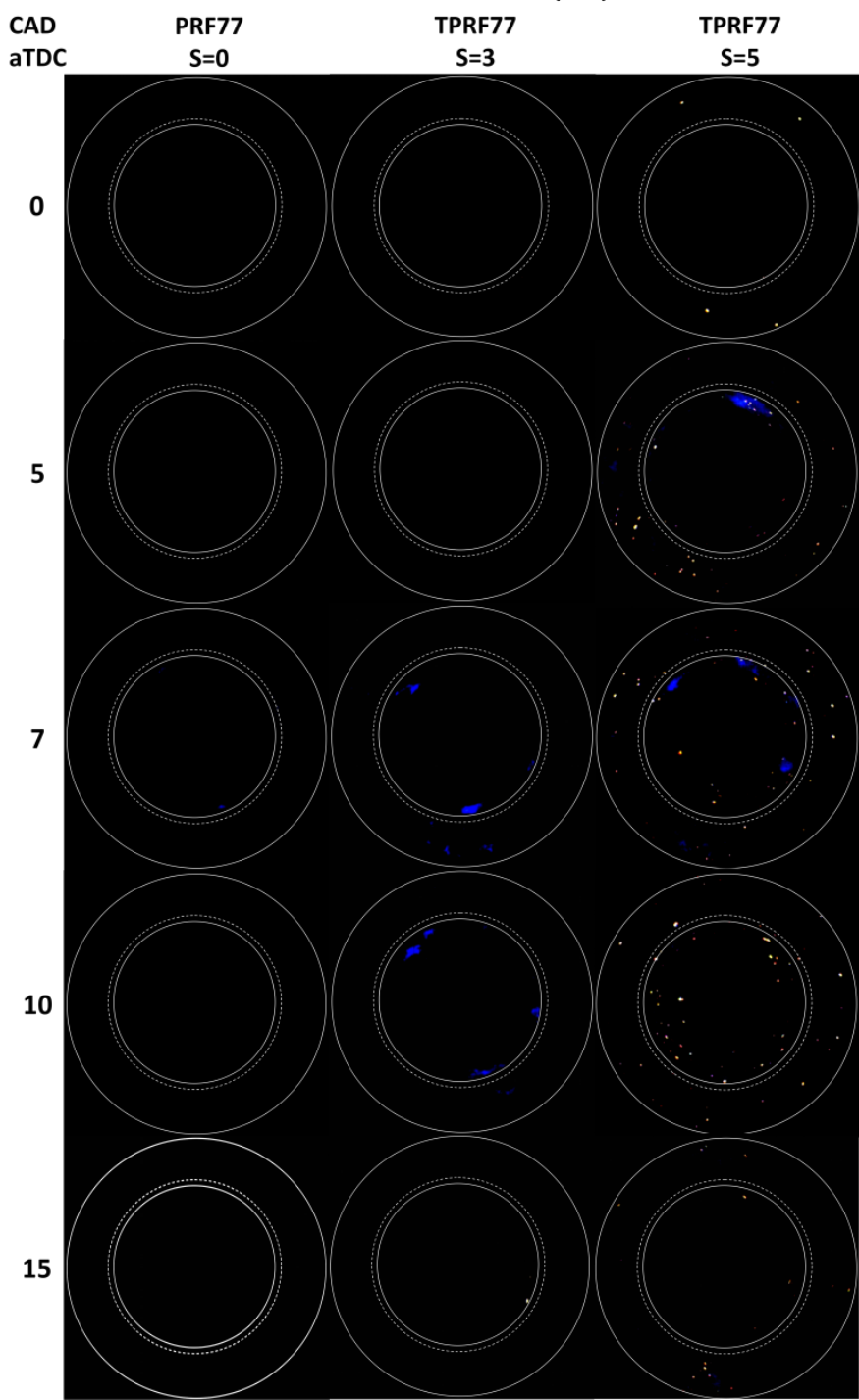

Fig. 11. The sequential combustion NFL images for test fuels with different sensitivities $(\mathrm{S}=0,3,5)$ at injection timing of $-60 \mathrm{CAD}$ aTDC

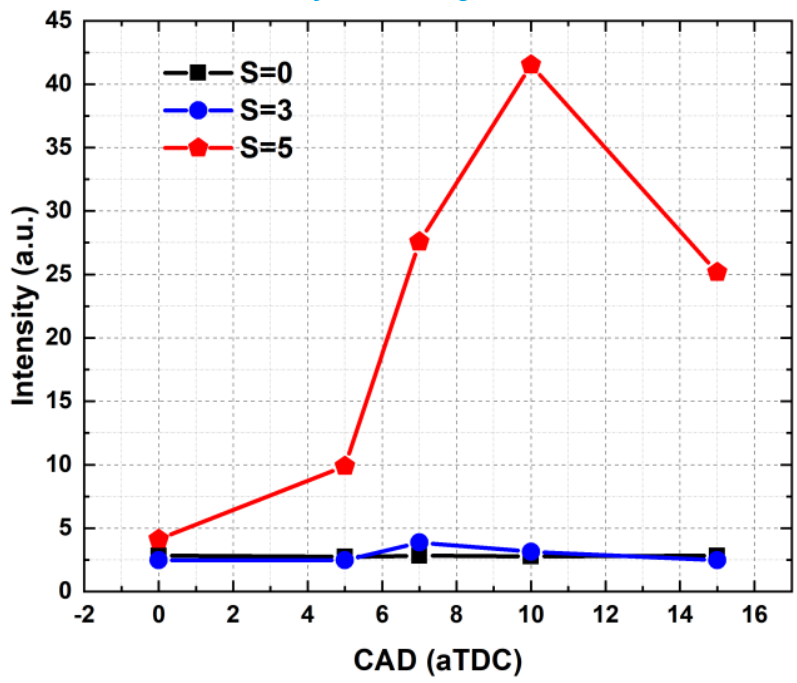

Fig. 12. The average intensity variations of combustion NFL images for test fuels with different sensitivities $(\mathrm{S}=0,3,5)$ at the injection timing of $-60 \mathrm{CAD}$ aTDC

Page 7 of 12

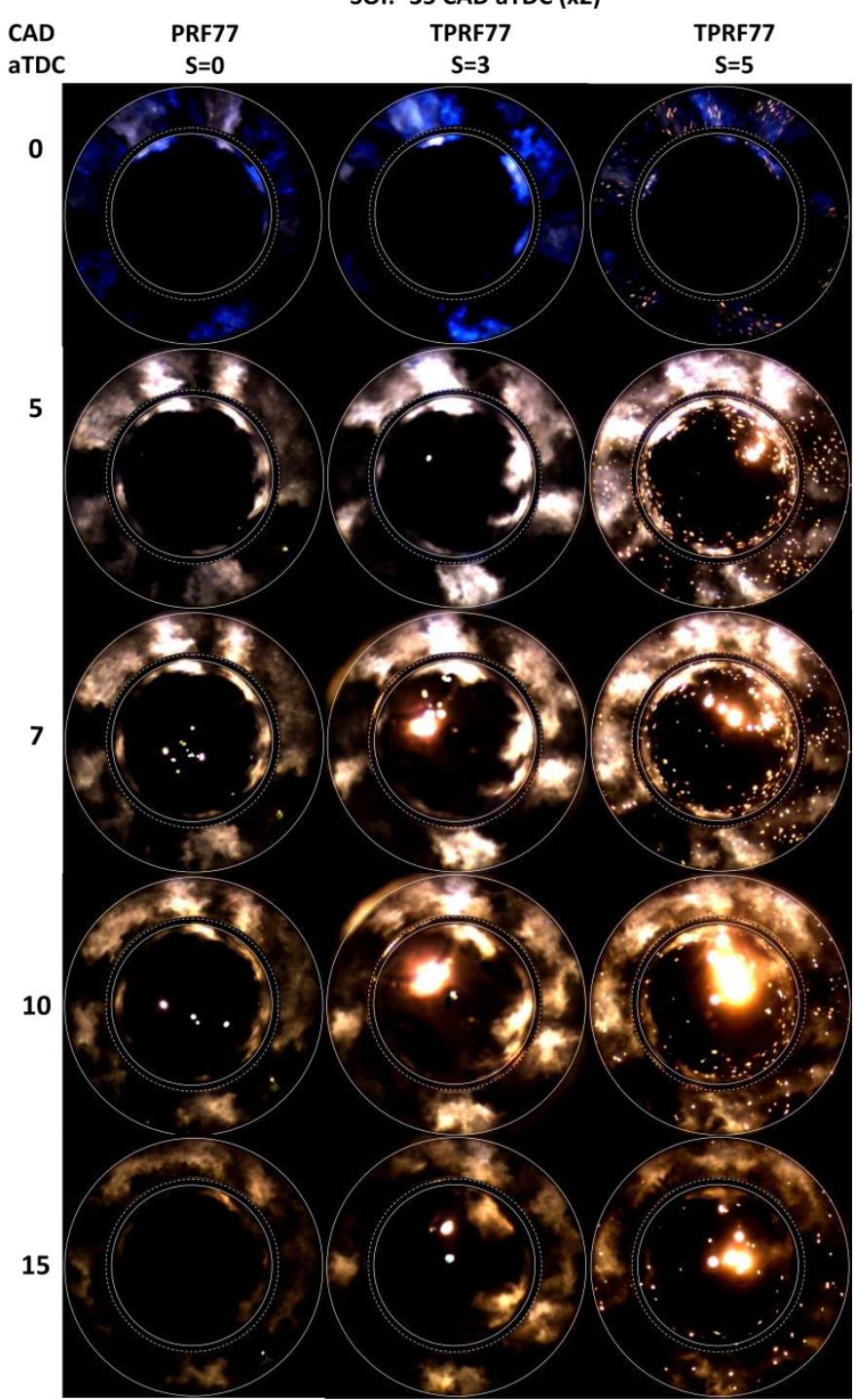

Fig. 13. The sequential combustion NFL images for test fuels with different sensitivities $(\mathrm{S}=0,3,5)$ at the injection timing of $-35 \mathrm{CAD}$ aTDC

Fig. 13 presents the in-cylinder combustion NFL images for test fuels with different sensitivities $(\mathrm{S}=0,3,5)$ at the injection timing of -35 CAD aTDC. During the combustion process, several isolated combustion clouds are distributed in the squish zone and piston bowl, since the fuel spray is divided into two parts after directly hitting on the piston rim between piston bowl and piston top land, as is shown in Fig. 3. Similarly, for the test fuel with $S=5$, there are many tiny spots appear in the combustion images and the combustion clouds tend to aggregate together. In addition, some dark yellow spots always grow in the cylinder center during the later stage of combustion for these test fuels, which is a result from injector dribbling [33]. Moreover, the higher fuel sensitivity, the more obvious of the injector dribbling. These phenomena imply that the fuel octane sensitivity has influences on the fuel vaporization process, and less fuel can be completely burnt when increasing the fuel OS by adding more toluene. 


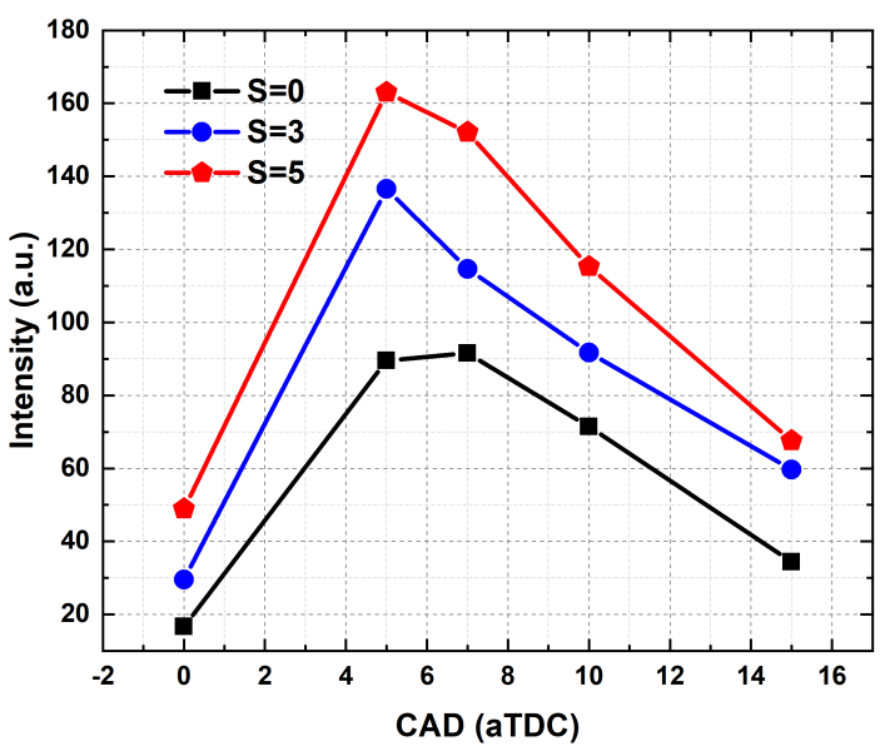

Fig. 14. The average intensity variations of combustion NFL images for test fuels with different sensitivities $(S=0,3,5)$ at the injection timing of -35 CAD aTDC

As is shown in Fig. 14, the average pixel intensities of combustion NFL images for all three test fuels follow similar trends, while the test fuel with higher sensitivity tends to get higher average intensity. This is due to that high fuel sensitivity is able to extend combustion duration and delay combustion phasing, which could retard the heat release phasing. Furthermore, the incomplete combustion resulted from high fuel sensitivity leads to more obvious injector dribbling and soot radiation, which also bring higher pixel intensity.

Fig. 15 shows the combustion process for three test fuels with the injection timing of -15 CAD aTDC. As this injection timing locates in the transition zone between PPC and CI, there is a large bulk of combustion cloud distributed in piston bowl for all test fuels, and this is consistent with fuel spray/wall interaction scheme shown in Fig. 3. Besides, when the late injection timing is employed under PPC mode, the combustion clouds are evolved in piston bowl, which is similar to the combustion characteristic of CI combustion mode. Comparing the combustion processes for the three test fuels, it is noticeable that the fuel with higher sensitivity tends to get larger flame cloud and the average intensity is higher as well. This is because of the delayed combustion phasing and longer combustion duration, resulting from higher fuel sensitivity.

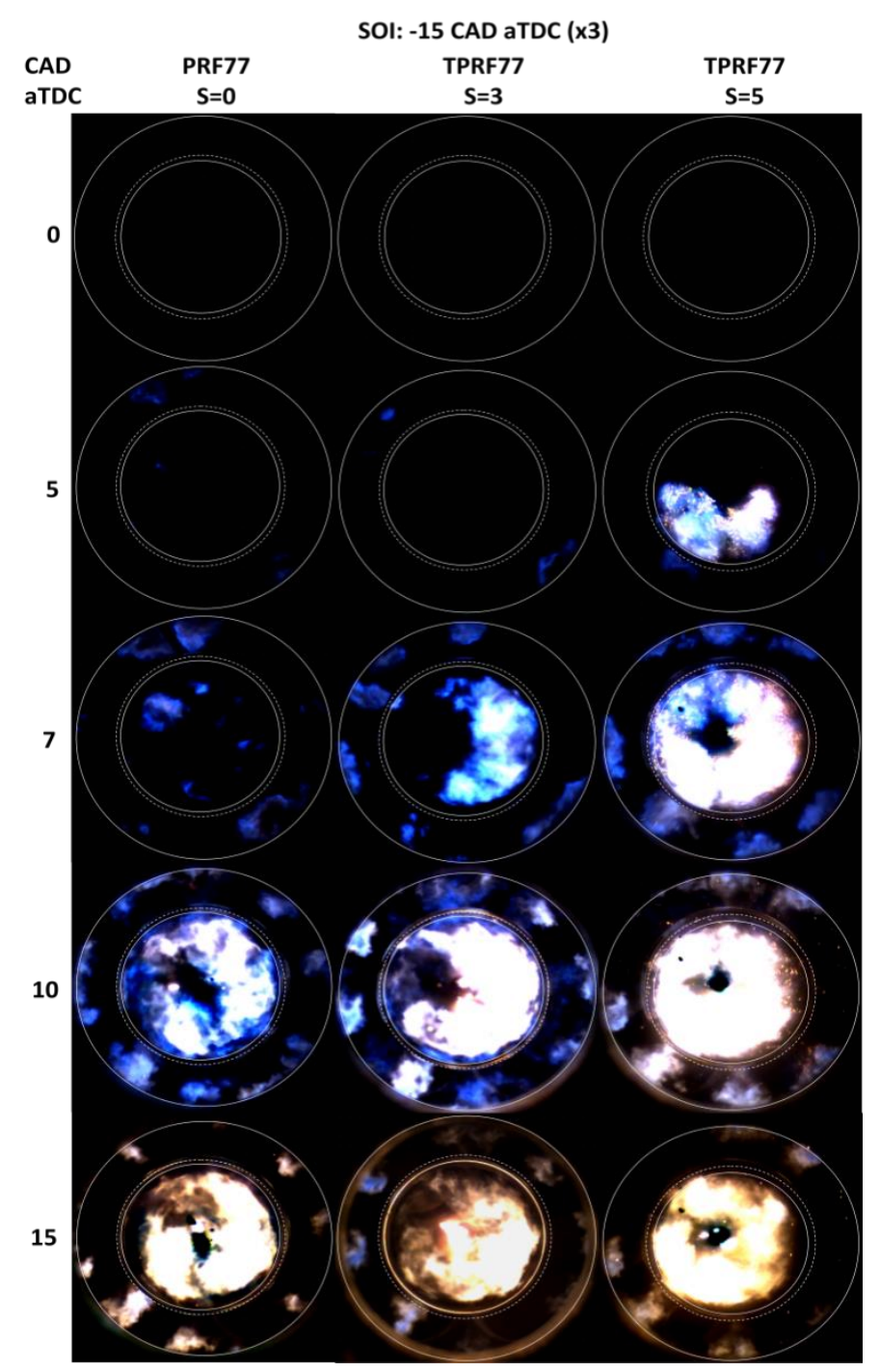

Fig. 15. The sequential combustion NFL images for test fuels with different sensitivities $(\mathrm{S}=0,3,5)$ at the injection timing of $-15 \mathrm{CAD}$ aTDC

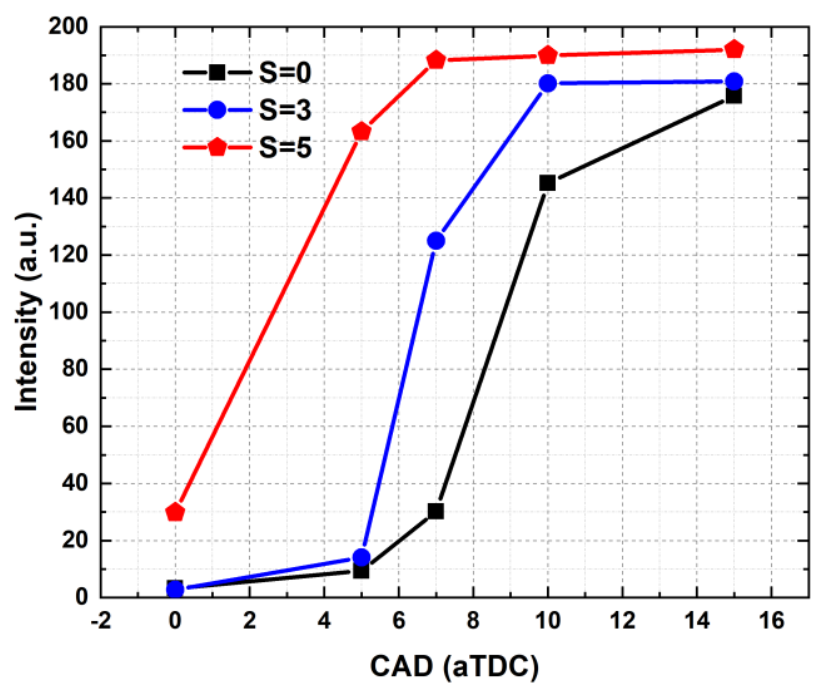

Fig. 16. The average intensity variations of combustion NFL images for test fuels with different sensitivities $(S=0,3,5)$ at the injection timing of -15 CAD aTDC

Page 8 of 12 
Similarly, as can be seen in Fig. 16, the average pixel intensities in combustion processes of all three test fuels with injection timing of 15 CAD aTDC follow the similar variation trend. In the early combustion stage, the test fuel with higher sensitivity have higher average intensity, this is consistent with the late combustion phasing of higher sensitive fuel, and incomplete combustion brought by fuel sensitivity result to higher soot radiation. Moreover, during the late stage of the combustion process, the average intensities of all three test fuels tend to be close to each other, this is because all test fuels tend to be completely burnt at the late stage of high-temperature combustion, and the fuel sensitivity effect is degraded.

\section{Summary/Conclusions}

In this study, the effect of fuel octane sensitivity on combustion characteristics under GCI-PPC mode is investigated in a fulltransparent single cylinder AVL optical engine. Practical $\omega$-shape quartz piston, as well as continuous firing mode (150 cycles), are employed to reproduce the real engine operating conditions. One binary blends PRF77 $(\mathrm{S}=0)$, two ternary blends TPRF77-a $(\mathrm{S}=3)$ and TPRF77-b $(\mathrm{S}=5)$, are selected as test fuels with different octane sensitivities. In addition, the high-speed natural flame luminosity imaging technology is applied to visualize the in-cylinder combustion process, and the related combustion characteristics and engine-out emissions are analyzed. The corresponding conclusions are listed as follows:

1) Similar trends of combustion characteristics (start of combustion, IDT, CA50, combustion duration) are confirmed for the different octane sensitivity fuels with regards to different injection timing under PPC mode. Moreover, the fuel with higher octane sensitivity generally leads to the delayed start of combustion, prolonged ignition delay time, retarded combustion phasing of CA50 as well as extended combustion duration, especially for early injection timing ranging from -40 to -35 CAD aTDC under PPC mode.

2) A higher IMEP tends to be generated with the higher octane sensitivity fuel under PPC mode at late injection timing of -15 CAD aTDC, further $4 \%$ increase of IMEP is achieved with the highest octane sensitivity fuel (TPRF77-b) as compared with zero sensitivity fuel (PRF77). In addition, the high fuel sensitivity could help to decrease the maximum in-cylinder pressure under PPC mode along with higher IMEP. Consequently, the naphtha fuels that display higher octane sensitivities, could be made fully application in GCI engine, which also result to better engine performance such as lower heat loss and higher IMEP.

3) During the combustion process, the average pixel intensity after TDC tends to be increased for test fuel with higher octane sensitivity, which also show some bright tiny spots caused by fuel spray vaporization effect.

4) The test fuel with higher sensitivity is more likely to produce higher UHC and CO emissions especially for early injection timing. In addition, the incomplete combustion of high octane sensitivity fuel comes from stronger injector dribbling and soot radiation.

\section{References}

1. An, Y., et al., In-cylinder combustion and soot evolution in the transition from conventional compression ignition (CI) mode to partially premixed combustion (PPC) mode. 2018. 32(2): p. 2306-2320.

2. Saxena, S., I.D.J.P.i.E. Bedoya, and C. Science, Fundamental phenomena affecting low temperature combustion and HCCI engines, high load limits and strategies for extending these limits. 2013. 39(5): p. 457-488.

3. Fathi, M., et al., Modeling and controller design architecture for cycle-by-cycle combustion control of homogeneous charge compression ignition (HCCI) engines-a comprehensive review. 2017. 139: p. 1-19.

4. An, Y., et al., Numerical simulation of combustion and soot under partially premixed combustion of low-octane gasoline. 2018. 211: p. 420-431.

5. Noehre, C., et al., Characterization of partially premixed combustion. 2006, SAE Technical Paper.

6. Johansson, B. High-load partially premixed combustion in a heavy-duty diesel engine. in Diesel engine emissions reduction (DEER) Conference. Chicago, Illinois. 2005.

7. Lewander, M., et al., Investigation of the combustion characteristics with focus on partially premixed combustion in a heavy duty engine. 2009. 1(1): p. 1063-1074.

8. Qiu, L., et al., Partially premixed combustion based on different injection strategies in a light-duty diesel engine. 2016. 96: p. 155-165.

9. Jain, A., A.P. Singh, and A.K.J.A.e. Agarwal, Effect of fuel injection parameters on combustion stability and emissions of a mineral diesel fueled partially premixed charge compression ignition (PCCI) engine. 2017. 190: p. 658-669.

10. Li, Z., et al., Effect of dimethyl ether (DME) addition on sooting limits in counterflow diffusion flames of ethylene at elevated pressures. 2018. 197: p. 463-470.

11. Shen, M., et al., Effects of EGR and intake pressure on PPC of conventional diesel, gasoline and ethanol in a heavy duty diesel engine. 2013, SAE Technical Paper.

12. Manente, V., B. Johansson, and P. Tunestal, Partially premixed combustion at high load using gasoline and ethanol, a comparison with diesel. 2009, SAE Technical Paper.

13. Manente, V., P. Tunestål, and B. Johansson. Half load partially premixed combustion, PPC, with high octane number fuels. gasoline and ethanol compared with diesel. in Symposium on International Automotive Technology: SIAT 2009. 2009.

14. Manente, V., B. Johansson, and W.J.I.J.o.E.R. Cannella, Gasoline partially premixed combustion, the future of internal combustion engines? 2011. 12(3): p. 194-208.

15. Kalghatgi, G.T., P. Risberg, and H.-E. Ångström, Partially pre-mixed auto-ignition of gasoline to attain low smoke and low NOx at high load in a compression ignition engine and comparison with a diesel fuel. 2007, SAE Technical paper.

16. Hildingsson, L., et al., Fuel octane effects in the partially premixed combustion regime in compression ignition engines. 2009, SAE Technical Paper.

17. Leermakers, C., et al., Low octane fuel composition effects on the load range capability of partially premixed combustion. 2014. 135: p. 210-222.

18. Chang, J., et al., Enabling high efficiency direct injection engine with naphtha fuel through partially premixed charge compression ignition combustion. 2012, SAE Technical Paper.

Page 9 of 12 
19. Shankar, B., et al., Primary reference fuels (PRFs) as surrogates for low sensitivity gasoline fuels. 2016.

20. Mittal, V., et al., The underlying physics and chemistry behind fuel sensitivity. 2010. 3(1): p. 256-265.

21. American Society of Testing Materials. D-2699 and D-2700. ASTM Research Method ASTM D 908 -56 and ASTM Motor Method ASTM D 357 -56. 1956.

22. Sarathy, S.M., et al., Compositional effects on the ignition of FACE gasolines. 2016. 169: p. 171-193.

23. Pitz, W.J., et al., Development of an experimental database and chemical kinetic models for surrogate gasoline fuels. 2007, SAE Technical Paper.

24. Jain, S.K., A.S. Badhe, and S.K. Aggarwal. Effect of Fuel Sensitivity on PAH Emissions in Low-Octane Naphtha Partially Premixed Flames. in 2018 AIAA Aerospace Sciences Meeting. 2018.

25. Leppard, W.R.J.S.t., The chemical origin of fuel octane sensitivity. 1990: p. 862-876.

26. Westbrook, C.K., et al., Chemical kinetics of octane sensitivity in a spark-ignition engine. 2017. 175: p. 2-15.

27. Jain, S.K. and S.K.J.F. Aggarwal, Compositional effects on the ignition and combustion of low octane fuels under diesel conditions. 2018. 220: p. 654-670.

28. Javed, T., et al., Ignition studies of n-heptane/isooctane/toluene blends. 2016. 171: p. 223-233.

29. Javed, T., et al., Ignition delay measurements of light naphtha: A fully blended low octane fuel. 2017. 36(1): p. 315-322.
30. Singh, E., et al., Chemical kinetic insights into the octane number and octane sensitivity of gasoline surrogate mixtures. 2017. 31(2): p. 1945-1960.

31. Szybist, J.P., D.A.J.C. Splitter, and Flame, Pressure and temperature effects on fuels with varying octane sensitivity at high load in SI engines. 2017. 177: p. 49-66.

32. Morgan, N., et al., Mapping surrogate gasoline compositions into RON/MON space. 2010. 157(6): p. 11221131.

33. An, Y., et al., Combustion stability study of partially premixed combustion with low-octane fuel at low engine load conditions. 2019. 235: p. 56-67.

34. An, Y., et al., Analysis of transition from HCCI to CI via PPC with low octane gasoline fuels using optical diagnostics and soot particle analysis. 2017, SAE Technical Paper.

\section{Contact Information}

Yanzhao An

Postdoc Fellow

Clean Combustion Research Center

King Abdullah University of Science and Technology, KAUST

Building 5, Level 4, room 4216-WS11, Thuwal 23955-6900,

Kingdom of Saudi Arabia

Mobile: +966 544701348

E-mail: yanzhao.an@kaust.edu.sa 


\section{Appendix}

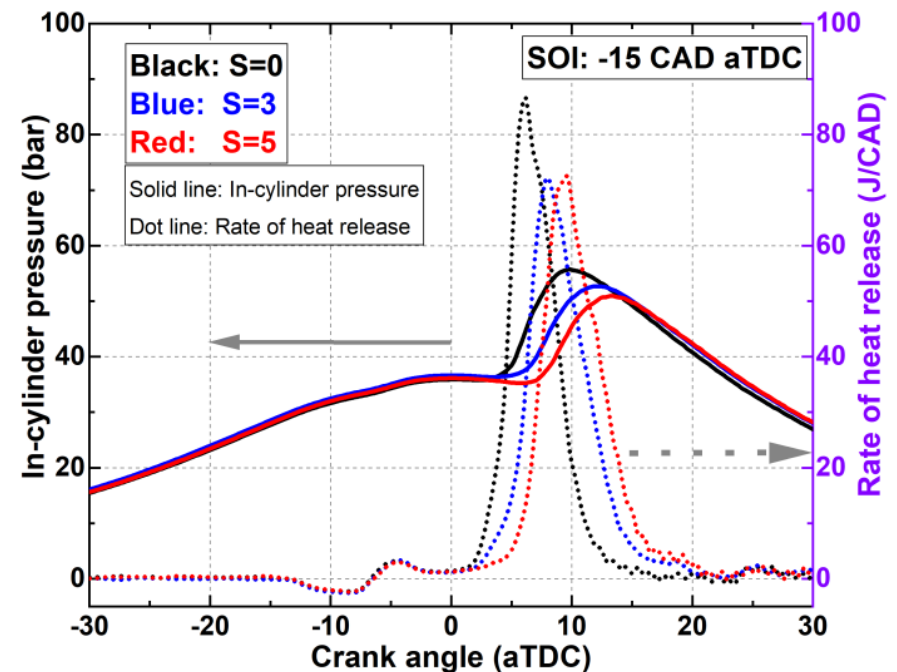

Fig. 1. The pressure and heat release $(S=0,3,5)$ at the injection timing of -15 CAD aTDC

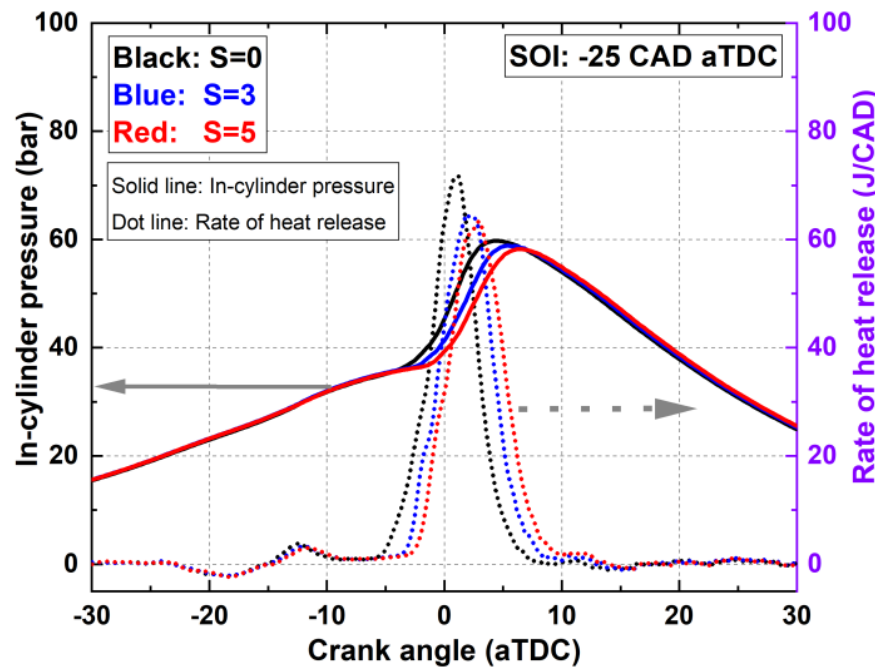

Fig. 3. The pressure and heat release $(\mathrm{S}=0,3,5)$ at the injection timing of -25 CAD aTDC

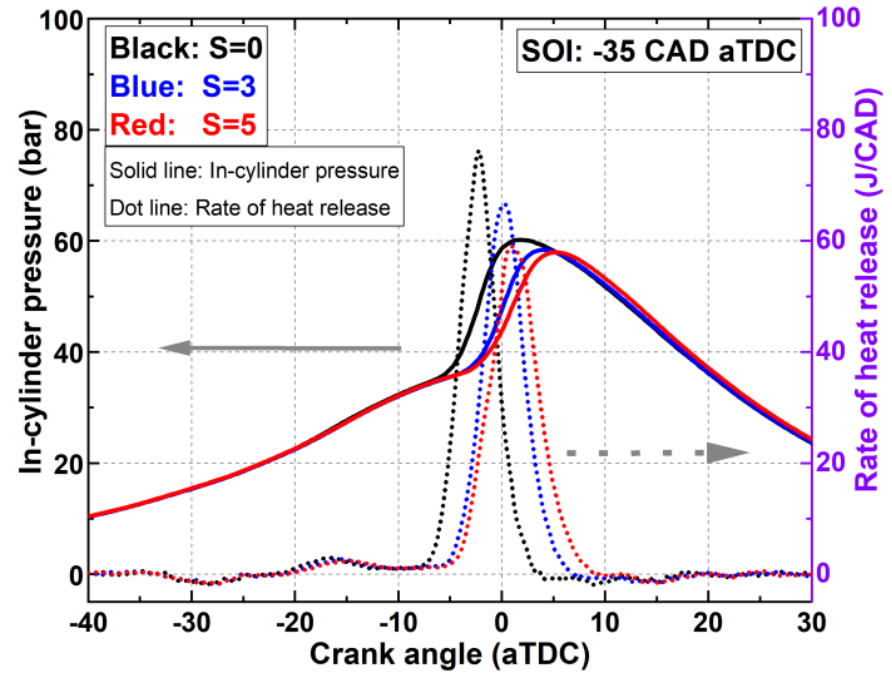

Fig. 5. The pressure and heat release $(\mathrm{S}=0,3,5)$ at the injection timing of -35 CAD aTDC

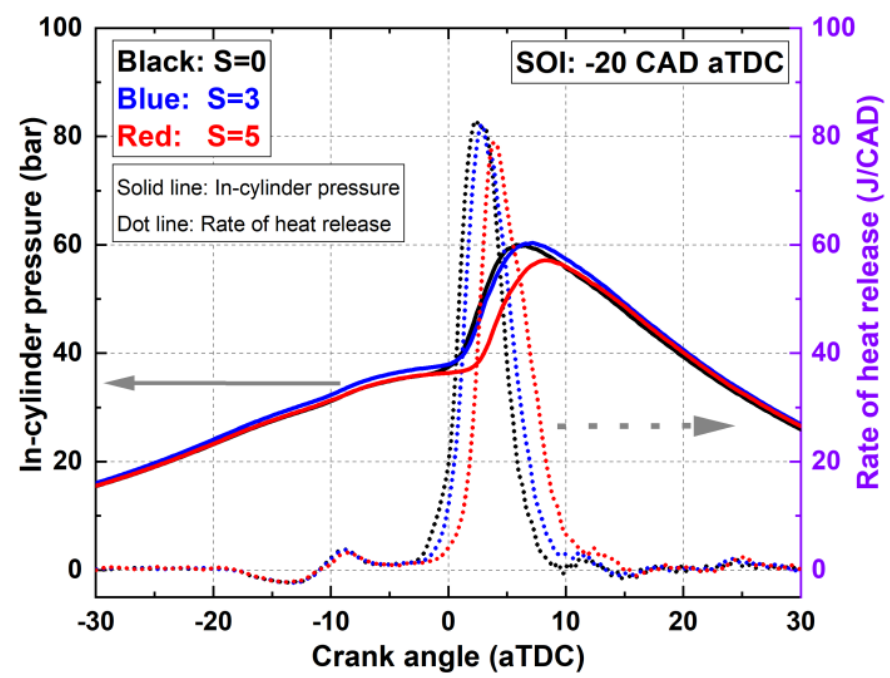

Fig. 2. The pressure and heat release $(\mathrm{S}=0,3,5)$ at the injection timing of -20 CAD aTDC

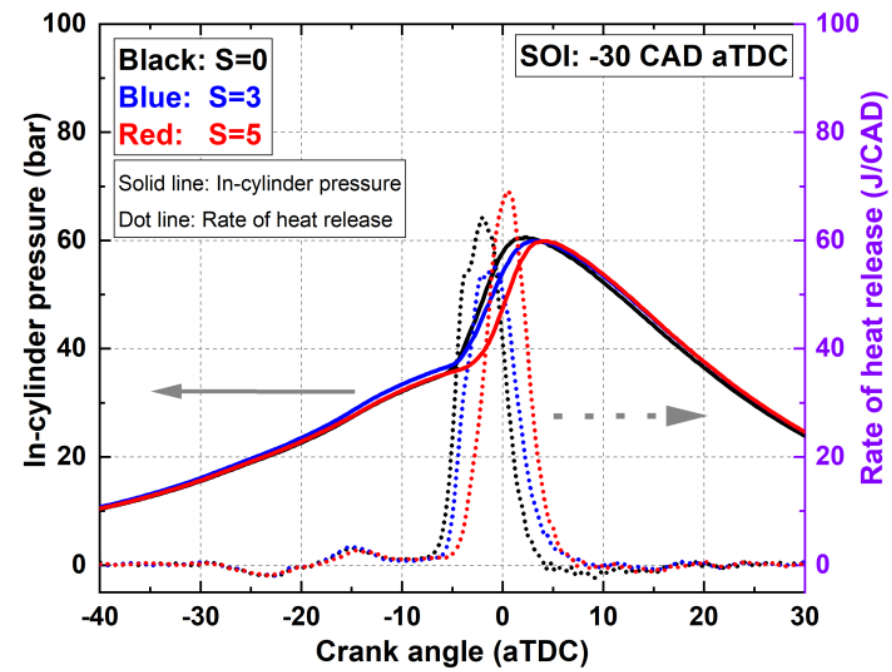

Fig. 4. The pressure and heat release $(S=0,3,5)$ at the injection timing of -30 CAD aTDC

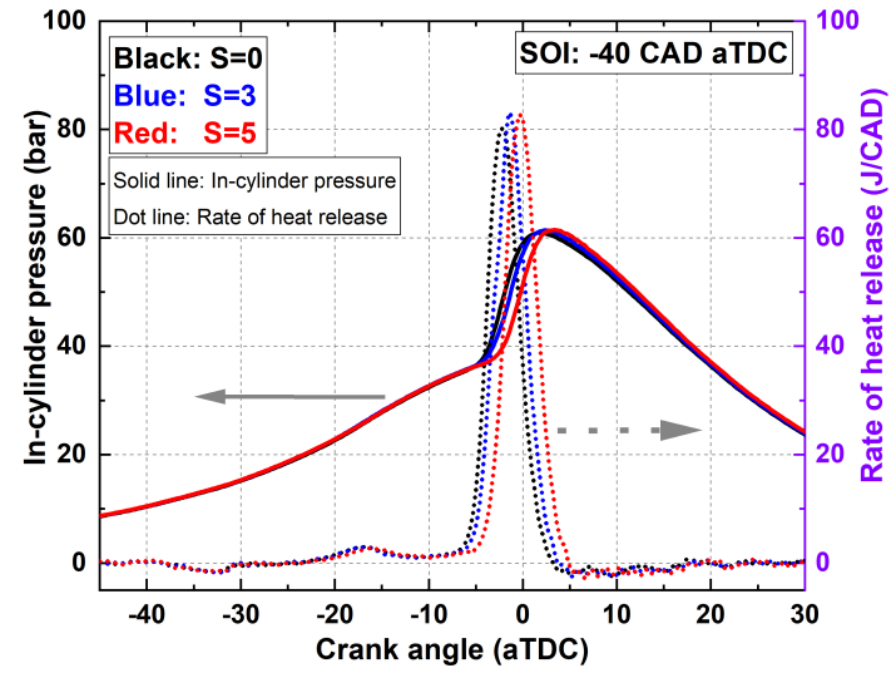

Fig. 6. The pressure and heat release $(\mathrm{S}=0,3,5)$ at the injection timing of -40 CAD aTDC

Page 11 of 12 


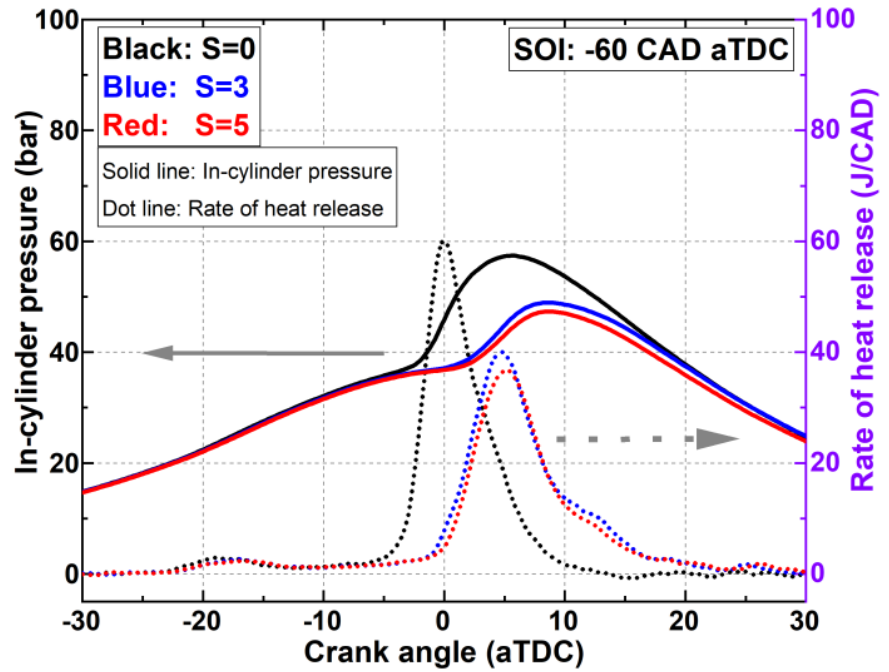

Fig. 7. The pressure and heat release $(\mathrm{S}=0,3,5)$ at the injection timing of -60 CAD aTDC

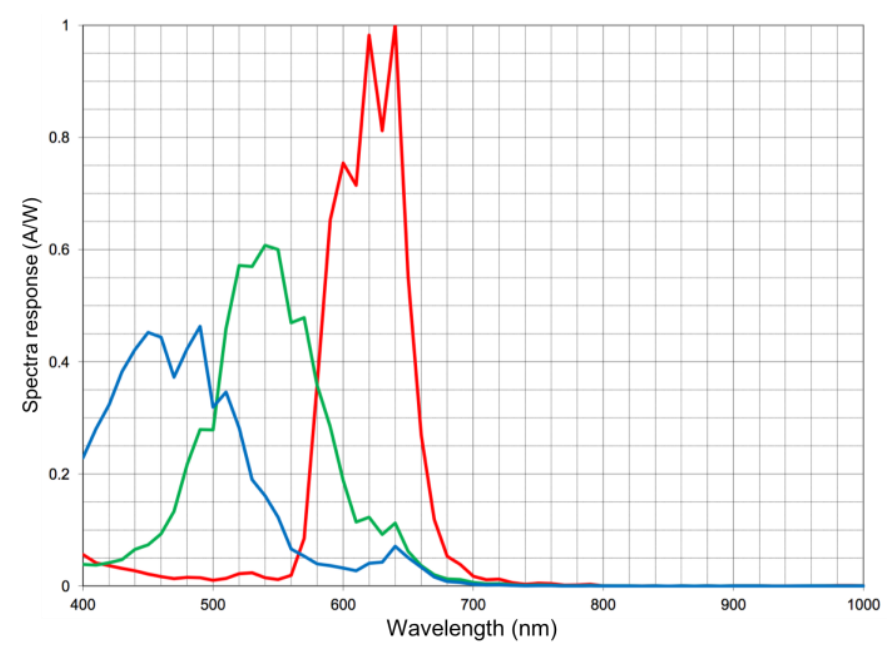

Fig. 8. The relative spectral response of the current color camera (FASTCAM SA4)

Page 12 of 12 